\title{
A Comparative Observational Study of the Use Transvaginal Ultrasound and Hysteroscopy for the Detection of Uterine Cavity Pathologies in Women with Abnormal Uterine Bleeding
}

\author{
Mervat Ali Mohamed Elsersy \\ Department of Obstetrics \& Gynecology, Faculty of Medicine, Alexandria University, Alexandria, Egypt \\ Email: msersy@hotmail.com
}

How to cite this paper: Elsersy, M.A.M. (2017) A Comparative Observational Study of the Use Transvaginal Ultrasound and Hysteroscopy for the Detection of Uterine Cavity Pathologies in Women with Abnormal Uterine Bleeding. Open Journal of Obstetrics and Gynecology, 7, 511-519. https://doi.org/10.4236/ojog.2017.75053

Received: April 17, 2017

Accepted: May 15, 2017

Published: May 18, 2017

Copyright $\odot 2017$ by author and Scientific Research Publishing Inc. This work is licensed under the Creative Commons Attribution International License (CC BY 4.0).

http://creativecommons.org/licenses/by/4.0/

\begin{abstract}
Background: $70 \%$ of all gynecological consultations are for abnormal uterine bleeding. Any approach to optimal management begins with an appropriate diagnosis. $40 \%$ of premenopausal women with abnormal uterine bleeding were found to have some intrauterine pathology. This study aims to compare the diagnostic value of transvaginal ultrasonography in comparison to hysteroscopy in detecting uterine abnormalities in patients with abnormal uterine bleeding. Methods: Retrospective observational cross sectional study of 250 women presented with abnormal uterine bleeding. The patients who fulfilled the selection criteria and have been sequentially investigated by transvaginal ultrasound (TVS) and hysteroscopy were included. Results: $90 \%$ of patients were from 35 - 49 yrs. $81.2 \%$ of patients have body mass index above $25 \mathrm{~kg} / \mathrm{m}^{2}$. Transvaginal ultrasound (TVS) compared well with high sensitivity as regards normal endometrium. (TVS) missed 4 patients of endometrial polyps and one patient of sub mucous fibroid. Three patients of adenomyosis were only diagnosed by (TVS); they were reported as being normal by hysteroscopy. Conclusion: (TVS) is considered as an excellent approach to the initial evaluation of uterine pathologies in patients with abnormal uterine bleeding.
\end{abstract}

\section{Keywords}

Transvaginal Ultrasound, Hysteroscopy, Abnormal Uterine Bleeding, Cross Section Observational Study, Endometrial Polyp

\section{Introduction}

Disturbances of menstrual bleeding can be manifested by a wide range of presentations. Abnormal uterine bleeding (AUB) is the broad term used to describe 
any change from normal menstruation or from a normal menstrual cycle pattern. The main features which should be discussed when describing (AUB) are regularity, frequency, heaviness of flow, and duration of flow, but each of these may exhibit considerable variations. Several abbreviations for these terminologies are established or becoming established by increasing popular usage [1].

(AUB) is nearly the most frequent cause of seeking gynecological consultation. In the reproductive age group in particular, $70 \%$ of all gynecological consultations are for abnormal uterine bleeding [2].

The aim of the diagnosis of abnormal uterine bleeding (AUB) is to identify the bleeding cause, which can be classified by the PALM-COEIN (Polyp, Adenomyosis, Leiomyoma, Malignancy (and hyperplasia), Coagulopathy, Ovulatory disorders, Endometrial, Iatrogenic and Not otherwise classified) classification system. In a gynecologic setting, the first step is usually to identify structural abnormalities (PALM causes).

Common diagnostic options for the identification of the PALM include ultrasonography, endometrial sampling, and hysteroscopy. These options alone or in combination are sufficient for the diagnosis of most women with AUB. Contrast sonography with saline or gel infusion, three-dimensional ultrasonography, and magnetic resonance imaging may be included [3]. 40\% of premenopausal women with abnormal uterine bleeding were found to have some intrauterine pathology [4].

Transvaginal ultrasound (TVS) has been considered as a relatively safe, noninvasive and simple procedure that gives a clear view of most uterine conditions. It helps to categorize patients with abnormal uterine bleeding so as to identify patients who require further evaluation; however several concerns have been raised regarding its accuracy [3] [5].

Hysteroscopy in comparison provides direct visualization of the uterine cavity and has an established diagnostic value for most of intrauterine pathologies. However, Hysteroscopy is expensive and requires specific equipment and in some patients, anesthesia is required [6] [7].

The potential hazards of (TVS) are not yet settled down especially in nonpregnant women. It is well known that endocavitary probes permits heat which rises transducer surface temperature up to $6^{\circ} \mathrm{C}$, and according to the safety guidelines of the British Medical Ultrasound Society (BMUS), it is recommended that when there is a Thermal Index (TI) of between 2.5 and 3.0, the scan time should be limited to less than 1 minute [8] [9]. Also the potential risk of getting infection through the transvaginal probe should be considered [10].

This study aimed to compare the diagnostic values of transvaginal ultrasonography in comparison to hysteroscopy in detecting uterine abnormalities in patients with abnormal uterine bleeding.

\section{Methods}

The present retrospective observational cross sectional trial was conducted in Hai Jamma hospital. The protocol was approved by institutional research com- 
mittee. Data of 250 women diagnosed with abnormal uterine bleeding were retrieved from the medical records. They fulfilled the selection criteria and have been investigated with transvaginal ultrasound and hysteroscopy sequentially in the duration from December 2014 to December 2015. The present study was conducted in accordance with the Declaration of Helsinki and a written informed consent was obtained from all the participants before hysteroscopy procedure.

\subsection{Selectioncriteria}

1) Inclusioncriteria: Any female presented with any change in her menstrual cycles for example changes in the rhythm, rate or the amount, or postmenopausal bleeding and she did not have any of the exclusion criteria.

2) Exclusion criteria: Haemodynamically unstable, virgin, pregnant, with coagulopathy, with enlarged uterus $>12$ weeks, with any cervical lesion which may be risky for hysteroscopy or clinically unfit patient who could not receive anesthesia

\subsection{Outcomes}

1) Primary outcome: Diagnosis of intrauterine pathology causing abnormal uterine bleeding.

2) Secondary outcome: Sensitivity, specificity, positive predicative value, negative predictive value of transvaginal ultrasound in relation to hysteroscopy as the golden standard in the detection of uterine pathologies causing abnormal uterine bleeding.

Data were collected from the patients' files. These data included,

- History and physical examination,

- Characterization of bleeding,

- Uterine size assessment,

- Report of transvaginal ultrasound which was performed with Aloka SSD1000 ultrasound system (Hitachi Aloka Medical, Ltd., Tokyo, Japan) and real-time scanners with $5.0 \mathrm{MHz}$ endovaginal transducers (Hitachi Aloka Medical, Ltd.),

- Report of hysteroscopy and biopsy: Hysteroscopy was performed with an 8-mm hysteroscope (Uteromat Fluid Control/A4060; Olympus Winter \& IBE $\mathrm{GmbH}$ ) with an 8.5-mm outer diameter that provides an oblique view of a 12 degree gradient with the optical axis. Distention of the uterine cavity during hysteroscopy was accomplished by normal saline insufflation.

\section{Results}

Abnormal uterine bleeding is a common and sometimes debilitating condition in women of reproductive age. Standardization of related terminology, a systematic approach to diagnosis and investigation is necessary. Management by the least invasive modalities which can achieve results which are considered satisfactory to the patient is the aim of all therapeutic interventions [11]. 
The data of the 250 patients who were included in the study was tabulated in Table 1. Analysis of these data revealed that the age of our patients ranged from 19 - 65 yrs with $90 \%$ of patients fell in the ( $35-49$ yrs) age group. The majority of the patients were multiparous with body mass index above $25 \mathrm{~kg} / \mathrm{m}^{2}$. According to the uterine size, $52.8 \%$ of the patients had normal size uteri, while $47.2 \%$ of patients had bulky uteri. According to the bleeding patterns, $42 \%$ of our patients had prolonged bleeding for more than 10 days per episode, $12 \%$ of our patient had frequent bleeding more than four episodes in 90 days. The most common abnormality to the bleeding pattern, was irregular bleeding i.e. the patients had a range of varying lengths of bleeding -free interval more than 17 days in one 90 days reference period.

Because the terminologies used to describe intrauterine cavity abnormalities differ between ultrasound and hysteroscopic reporting system. So in this study ultrasound finding of normal endometrium was matched and correlated with hysteroscopic finding of no abnormality, alsoreporting of thin endometrium by (TVS) corresponded to atrophic endometrium as a hysteroscopic findings. The (TVS) report of thickendometrium matched with shaggy polypoidal endome-

Table 1. Shows the demographic and clinical data of all patients of the study $(n=250)$.

\begin{tabular}{|c|c|}
\hline & No. (\%) \\
\hline \multicolumn{2}{|l|}{ Age(years) } \\
\hline $19-35$ & $14(5.6 \%)$ \\
\hline $35-49$ & $225(90.0 \%)$ \\
\hline$>49$ & $11(4.4 \%)$ \\
\hline \multicolumn{2}{|l|}{ Parity } \\
\hline $\mathrm{P} 1$ & $13(5.2 \%)$ \\
\hline $\mathrm{P} 2$ & $118(47.2 \%)$ \\
\hline $\mathrm{P} 3$ & $92(36.8 \%)$ \\
\hline$\geq \mathrm{p} 4$ & $27(10.8 \%)$ \\
\hline \multicolumn{2}{|l|}{ Body mass index $\left(\mathrm{kg} / \mathrm{m}^{2}\right) \dagger$} \\
\hline$<19$ & $13(5.2 \%)$ \\
\hline $19-25$ & $34(13.6 \%)$ \\
\hline$>25$ & $203(81.2 \%)$ \\
\hline \multicolumn{2}{|l|}{ Uterine size clinically assessed in weeks of gestation } \\
\hline Normal size & $132(52.8 \%)$ \\
\hline Bulky 10 - 12 weeks & $118(47.2 \%)$ \\
\hline \multicolumn{2}{|l|}{ Bleeding characterization } \\
\hline Prolonged bleeding: 10 days in one episode & $105(42.0 \%)$ \\
\hline Frequent bleeding: $>4$ episodes in one 90 -day reference period & $30(12.0 \%)$ \\
\hline $\begin{array}{l}\text { Irregular bleeding: A range of varying lengths of bleeding-free intervals > } \\
17 \text { days within one } 90 \text {-day reference period }\end{array}$ & $115(46.0 \%)$ \\
\hline
\end{tabular}

${ }^{\dagger}$ kilogram per meter square; Qualitative data were described using number and percent. 
Table 2. Correlation of transvaginal ultrasound and hysteroscopic for the same findings.

\begin{tabular}{cccc}
\hline Transvaginal ultrasound findings & No. (\%) & Hysteroscopic findings & No. (\%) \\
\hline Normal endometrium & $137(54.8 \%)$ & No abnormality & $140(56.0 \%)$ \\
Thin endometrium $<5 \mathrm{~mm}$ & $6(2.4 \%)$ & Atrophic endometrium & $5(2.0 \%)$ \\
Thick endometrial & $45(18 \%)$ & Shaggy polypoidal endometrium & $40(16.0 \%)$ \\
Endometrial polyp & $40(16.0 \%)$ & Endometrial polyp & $44(17.6 \%)$ \\
Irregular heterogeneous content & $4(1.6 \%)$ & Irregular tissues diagnosed later as remnants of conception & $4(1.6 \%)$ \\
Sub mucous fibroids & $15(6.0 \%)$ & Sub mucous fibroids & $16(6.4 \%)$ \\
adenomyosis & $3(1.2 \%)$ & Adenomyosis & $0(0.0 \%)$ \\
Endometritis & $0(0.0 \%)$ & Endometritis & $1(0.4 \%)$ \\
\hline
\end{tabular}

Qualitative data were described using number and percent.

trium as reported by hysteroscopic examination as shown in Table 2 .

Analysis of data revealed that out of 140 patients were diagnosed to have no abnormality by hysteroscopic examination, 137 of them was reported to have normal endometrium by (TVS). Also 44 patients were diagnosed to have endometrial polyps by hysteroscopy, only 40 of them were reported to have endometrial polyps by (TVS). Hysteroscopy failed to diagnose 3 patients diagnosed to have adenomyosis by (TVS). Also (TVS) failed to diagnose any case of endometritis whom were diagnosed by hysteroscopy.

As shown in Table 3, (TVS)-hysteroscopy correlation sub group analysis revealed that the 137 patients whom their reports were of normal endometrium by (TVS), only 135 patients were reported to have hysteroscopic reports of no abnormality. One patient of those 137 patients was reported to have endometrial polyp and another one patient was reported to have endometritis, i.e. (TVS) missed one patient of endometrial polyp.

Also analysis of data of the 45 reports of thick endometrium by (TVS), only 40 of them was truly diagnosed to have polypoidal endometrium while 3 of them were reported to have endometrial polyps i.e. (TVS) missed another 3patients of endometrial polyps, one patient of submucous myoma and another one of remnants of conception. Analysis of data of the 4 patients who were reported to have irregular heterogeneous contents which were believed to have remnants of conception before hysteroscopy, only 2 of them were diagnosed to have remnants of conception. (TVS) was superior to hysteroscopy in the diagnosis of the three patients reported to have adenomyosis, may be because adenomyosis in a disease involving the uterine cavity as shown in Table 3.

Analysis of data showed very good agreement of (TVS) findings to hysteroscopy which is considered the golden standard tool to diagnose intrauterine abnormalities as tabulated in Table 4. Focusing on the more commonly diagnosed pathologiesas submucous myoma, endometrial polyp, thick endometrium and normal endometrium. (TVS) had sensitivity of $99.57 \%$, specificity of $87.5 \%$, and a positive predictive value of $99.15 \%$ and negative predictive value of $93.33 \%$ for the diagnosis of submucous myoma, with Kappa value of 0.897 . Also (TVS) had 
Table 3. (TVS)-hysteroscopy correlation sub group analysis.

\begin{tabular}{|c|c|c|c|}
\hline Transvaginal ultrasound findings & & Hysteroscopic findings & \\
\hline $\begin{array}{l}\text { Normal endometrium proliferative phase } \\
\qquad<10 \mathrm{~mm}\end{array}$ & 137 & $\begin{array}{l}\text { No abnormality } \\
\text { Endometrial polyp } \\
\text { endometritis }\end{array}$ & $\begin{array}{c}135 \\
1 \\
1\end{array}$ \\
\hline Thin endometrium $<5 \mathrm{~mm}$ & 6 & $\begin{array}{l}\text { Atrophic endometrium } \\
\text { No abnormality }\end{array}$ & $\begin{array}{l}5 \\
1\end{array}$ \\
\hline Thick endometrial interface $>10 \mathrm{~mm}$ & 45 & $\begin{array}{l}\text { Shaggy polypoidal endometrium } \\
\text { Endometrial polyp } \\
\text { Sub mucous myoma } \\
\text { remnants of conception }\end{array}$ & $\begin{array}{c}40 \\
3 \\
1 \\
1\end{array}$ \\
\hline Irregular heterogeneous content & 4 & $\begin{array}{l}\text { remnants of conception } \\
\text { No abnormality } \\
\text { Submucous myoma }\end{array}$ & $\begin{array}{l}2 \\
1 \\
1\end{array}$ \\
\hline Sub mucous fibroids & 15 & $\begin{array}{l}\text { Submucous myoma } \\
\text { Remnants of conception }\end{array}$ & $\begin{array}{c}14 \\
1\end{array}$ \\
\hline Endometrial polyp & 40 & Endometrial polyp & 40 \\
\hline Adenomyosis & 3 & No abnormality & 3 \\
\hline
\end{tabular}

Table 4. Transvaginal ultrasound performance.

\begin{tabular}{|c|c|c|c|c|c|}
\hline & $\begin{array}{l}\text { Sensitivity } \\
(95 \% \mathrm{CI})^{*}\end{array}$ & $\begin{array}{l}\text { Specificity } \\
(95 \% \mathrm{CI})\end{array}$ & $\begin{array}{c}\mathrm{PPV} \dagger \\
(95 \% \mathrm{CI})\end{array}$ & $\begin{array}{c}\text { NPV } \ddagger \\
(95 \% \mathrm{CI})\end{array}$ & Kappa value \\
\hline Sub mucous fibroids & $\begin{array}{c}99.57 \\
(97.64-99.99)\end{array}$ & $\begin{array}{c}87.50 \\
(61.65-98.45\end{array}$ & $\begin{array}{c}99.15 \\
(96.96-99.90)\end{array}$ & $\begin{array}{c}93.33 \\
(68.05-99.83)\end{array}$ & $\begin{array}{c}0.897 \\
\text { (Very good agreement) }\end{array}$ \\
\hline Endometrial polyp & $\begin{array}{c}100.0 \\
(98.23-100.0)\end{array}$ & $\begin{array}{c}90.91 \\
(78.33-97.47)\end{array}$ & $\begin{array}{c}98.10 \\
(95.20-99.48\end{array}$ & $\begin{array}{c}100.0 \\
(91.19-100.0)\end{array}$ & $\begin{array}{c}0.943 \\
\text { (Very good agreement) }\end{array}$ \\
\hline Thick endometrial interface $>10 \mathrm{~mm}$ & $\begin{array}{c}97.62 \\
(94.53-99.22)\end{array}$ & $\begin{array}{c}100.0 \\
(91.19-100.0)\end{array}$ & $\begin{array}{c}100.0 \\
(98.22-100.0)\end{array}$ & $\begin{array}{c}88.89 \\
(75.95-96.29)\end{array}$ & $\begin{array}{c}0.929 \\
\text { (Very good agreement) }\end{array}$ \\
\hline $\begin{array}{c}\text { Normal endometrium proliferative } \\
\text { phase }<10 \mathrm{~mm}\end{array}$ & $\begin{array}{c}98.18 \\
(93.59-99.78)\end{array}$ & $\begin{array}{c}96.43 \\
(91.86-98.83)\end{array}$ & $\begin{array}{c}95.58 \\
(89.98-98.55)\end{array}$ & $\begin{array}{c}98.54 \\
(94.83-99.82)\end{array}$ & $\begin{array}{c}0.943 \\
\text { (Very good agreement) }\end{array}$ \\
\hline
\end{tabular}

$\dagger$ Positive predicative value. $¥$ Negative predictive value. ${ }^{\star} 95 \%$ confidential interval. Statistical analysis of the data; Data were fed to the computer and analyzed using IBM SPSS software package version 20.0. Agreement between markers was done using Sensitivity, Specificity, PPV, NPV and Kappa.

$100 \%$ sensitivity, $90.91 \%$ specificity, $98.1 \%$ a positive predictive value and $100 \%$ of negative predictive value for diagnosis of endometrial polyps. As regards the diagnosis of thick endometrium as a sole diagnosis (TVS) achieved $97.62 \%$ sensitivity, $100 \%$ specificity, $100 \%$ positive predictive value and $88.89 \%$ negative predictive value with kappa value of 0.929 which is considered as a very good achievement.

Data were fed to the computer and analyzed using IBM SPSS software package version 20.0. Agreement between markers was done using Sensitivity, Specificity, PPV, NPV and Kappa. 


\section{Discussion}

Abnormal uterine bleeding is a public health problem exceeded only by abnormal vaginal discharge as a reason for medical consultation.

Abnormal uterine bleeding imposes substantial demands on health service resources. Accurate diagnosis is of ultimate importance to achieve effective treatment, reducing morbidity and reducing mortality. There are many tests available, including transvaginal scan (TVS), endometrial biopsy, and saline infusion sonography and outpatient hysteroscopy; however, optimal diagnostic work-up is unclear [6].

Advances in ultrasound scanning technology have improved the noninvasive diagnosis of uterine pathology [12]. However, despite these developments, it is still not possible to visualize some problems with confidence, such as intrauterine adhesions, differentiating submucous fibroids from endometrial polyps can be difficult sometimes [13].

In this study, we compared the diagnostic accuracy of (TVS) to hysteroscopy to detect uterine pathologies causing abnormal uterine bleeding.

In this study, $54.8 \%$ of the patients had normal endometrium on (TVS), which is comparable to results of Goyal, B.K. et al. who found that $57 \%$ of their patients to have also normal endometrium [14].

In this study (TVU) had a high sensitivity, positive and negative predictive values in the diagnosis of normal and abnormal uterine cavity pathologies. These observations were similar to those observed by Goyal, B.K. et al. who recommended the use of trans vaginal ultrasound solely prior to initiation of treatment whenever there is no abnormal findings could be detected and to consider hysteroscopy whenever there is no response to medical treatment [14].

Also the findings of this study are similar to those observed by Ozer, A et al. who concluded that if there is no facility for hysteroscopy or hysteroscopyguided endometrial biopsy for women with abnormal uterine bleeding, transvaginal ultrasonography findings can be efficiently used to make a preliminary diagnosis [12].

Also Huili Zhu et al. found in their study that the sensitivity, specificity, positive predictive value and negative predictive value of (TVS) in the detection of endometrial polyps (EP) were $67.96 \%, 88.23 \%$ and $86.49 \%$, respectively [15].

Also Herman et al. recommended the transvaginal ultrasound to be the first step in imaging tests and other diagnostic tests should only be performed when indicated [16].

Our findings are different from those observed by Wanderley et al. who concluded that hysteroscopy revealed a diagnostic accuracy higher for all the diseases evaluated, while transvaginal ultrasonography showed an accuracy of $65.9 \%$ for polyps, $78.1 \%$ for myoma and $63.2 \%$ for endometrial hyperplasia.

They also observed that within the 57 patients submitted to uterine curettage, there was an accuracy of $56 \%$ for polyps and $54.6 \%$ for endometrial hyperplasia. They recommended that after initial investigation with transvaginal ultrasonography, guided biopsy of the lesion should be performed by hysteroscopy when- 
ever necessary in order to improve the diagnostic accuracy and subsequent clinical management [17].

Relatively different findings were observed also by Towbin et al. who observed that office hysteroscopy was $79 \%$ sensitive and $93 \%$ specific in diagnosing intracavitary pathologic disorders, whereas transvaginal ultrasonography was only $54 \%$ sensitive and $90 \%$ specific. They concluded that office hysteroscopy is a rapid, safe, well-tolerated, and highly accurate means of diagnosing the cause of excessive uterine bleeding [18].

In this study, no long-term follow-up was performed to detect any long-term complications for either (TVS) or hysteroscopy, so we recommend for further researches to study the long term consequences of the use of (TVS).

In this study, the main conclusion is that, (TVS) is considered as an excellent approach for the initial evaluation of uterine pathologies in patients with abnormal uterine bleeding.

\section{Acknowledgements}

I would like to thank all members of the medical record department, radiology department and staff of the operating room.

\section{References}

[1] Gynecologic Endocrinology Subgroup, Chinese Society of Obstetrics and Gynecology, Chinese Medical Association (2014) [Guideline on Diagnosis and Treatment of Abnormal Uterine Bleeding]. Chinese Journal of Obstetrics and Gynecology, 49, 801-806.

[2] Matthews, M.L. (2015) Abnormal Uterine Bleeding in Reproductive-Aged Women. Obstetrics \& Gynecology Clinics of North America, 42, 103-115.

https://doi.org/10.1016/j.ogc.2014.09.006

[3] Dueholm, M. and Hjorth, I.M. (2017) Structured Imaging Technique in the Gynecologic Office for the Diagnosis of Abnormal Uterine Bleeding. Best Practice \& Research Clinical Obstetrics \& Gynaecology, 40, 23-43.

[4] Goldstein, S.R. (2004) Menorrhagia and Abnormal Bleeding before the Menopause. Best Practice \& Research Clinical Obstetrics \& Gynaecology, 18, 59-69. https://doi.org/10.1016/j.bpobgyn.2003.10.003

[5] Babacan, A., et al. (2014) Comparison of Transvaginal Ultrasonography and Hysteroscopy in the Diagnosis of Uterine Pathologies. International Journal of Clinical and Experimental Medicine, 7, 764-769.

[6] Cooper, N.A., et al. (2014) Cost-Effectiveness of Diagnostic Strategies for the Management of Abnormal Uterine Bleeding (Heavy Menstrual Bleeding and Post-Menopausal Bleeding): A Decision Analysis. Health Technology Assessment, 18, 1-201, v-vi. https://doi.org/10.3310/hta18540

[7] Capmas, P., Sauvan, M. and Fernandez, H. (2015) Office Hysteroscopy in Postmenopausal Women: Feasibility and Correlation with Transvaginal Ultrasound. Journal of Minimally Invasive Gynecology, 22, S181.

https://doi.org/10.1016/j.jmig.2015.08.668

[8] Barnett, S.B., et al. (2000) International Recommendations and Guidelines for the Safe Use of Diagnostic Ultrasound in Medicine. Ultrasound in Medicine \& Biology, 26, 355-366. https://doi.org/10.1016/S0301-5629(00)00204-0 
[9] Karagoz, I. and Kartal, M.K. (2009) A New Safety Parameter for Diagnostic Ultrasound Thermal Bioeffects: Safe Use Time. Journal of the Acoustical Society of America, 125, 3601-3610. https://doi.org/10.1121/1.3126525

[10] Skowronek, P., et al. (2016) Can Diagnostic Ultrasound Scanners Be a Potential Vector of Opportunistic Bacterial Infection? Medical Ultrasonography, 18, 326-331. https://doi.org/10.11152/mu.2013.2066.183.sko

[11] Singh, S., et al. (2013) Abnormal Uterine Bleeding in Pre-Menopausal Women. Journal of Obstetrics and Gynaecology Canada, 35, 473-4. https://doi.org/10.1016/S1701-2163(15)30939-7

[12] Ozer, A., Ozer, S. and Kanat-Pektas, M. (2016) Correlation between Transvaginal Ultrasound Measured Endometrial Thickness and Histopathological Findings in Turkish Women with Abnormal Uterine Bleeding. Journal of Obstetrics and Gynaecology Research, 42, 573-578. https://doi.org/10.1111/jog.12937

[13] Carneiro, M.M. (2014) What Is the Role of Hysteroscopic Surgery in the Management of Female Infertility? A Review of the Literature. Surgery Research and Practice, 2014, Article ID: 105412.

[14] Goyal, B.K., et al. (2015) Transvaginal Sonography versus Hysteroscopy in Evaluation of Abnormal Uterine Bleeding. Medical Journal Armed Forces India, 71, 120 125. https://doi.org/10.1016/j.mjafi.2014.12.001

[15] Zhu, H., et al. (2016) Evaluation of Transvaginal Sonography in Detecting Endometrial Polyps and the Pregnancy Outcome Following Hysteroscopic Polypectomy in Infertile Women. Experimental and Therapeutic Medicine, 12, 1196-1200.

[16] Herman, M.C., Mol, B.W. and Bongers, M.Y. (2016) Diagnosis of Heavy Menstrual Bleeding. Women's Health, 12, 15-20. https://doi.org/10.2217/whe.15.90

[17] Wanderley, M.D., et al. (2016) Accuracy of Transvaginal Ultrasonography, Hysteroscopy and Uterine Curettage in Evaluating Endometrial Pathologies. Revista Brasileira de Ginecologia e Obstetrícia, 38, 506-511.

https://doi.org/10.1055/s-0036-1593774

[18] Towbin, N.A., Gviazda, I.M. and March, C.M. (1996) Office Hysteroscopy versus Transvaginal Ultrasonography in the Evaluation of Patients with Excessive Uterine Bleeding. American Journal of Obstetrics \& Gynecology, 174, 1678-1682. https://doi.org/10.1016/S0002-9378(96)70196-5

\section{Submit or recommend next manuscript to SCIRP and we will provide best service for you:}

Accepting pre-submission inquiries through Email, Facebook, LinkedIn, Twitter, etc. A wide selection of journals (inclusive of 9 subjects, more than 200 journals) Providing 24-hour high-quality service User-friendly online submission system Fair and swift peer-review system Efficient typesetting and proofreading procedure Display of the result of downloads and visits, as well as the number of cited articles Maximum dissemination of your research work

Submit your manuscript at: http://papersubmission.scirp.org/ Or contact ojog@scirp.org 